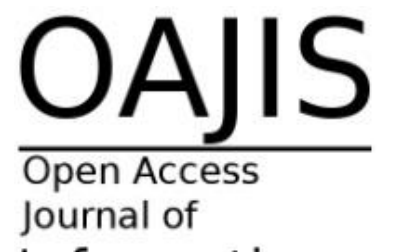

Information

Systems

is.its.ac.id/pubs/oajis/
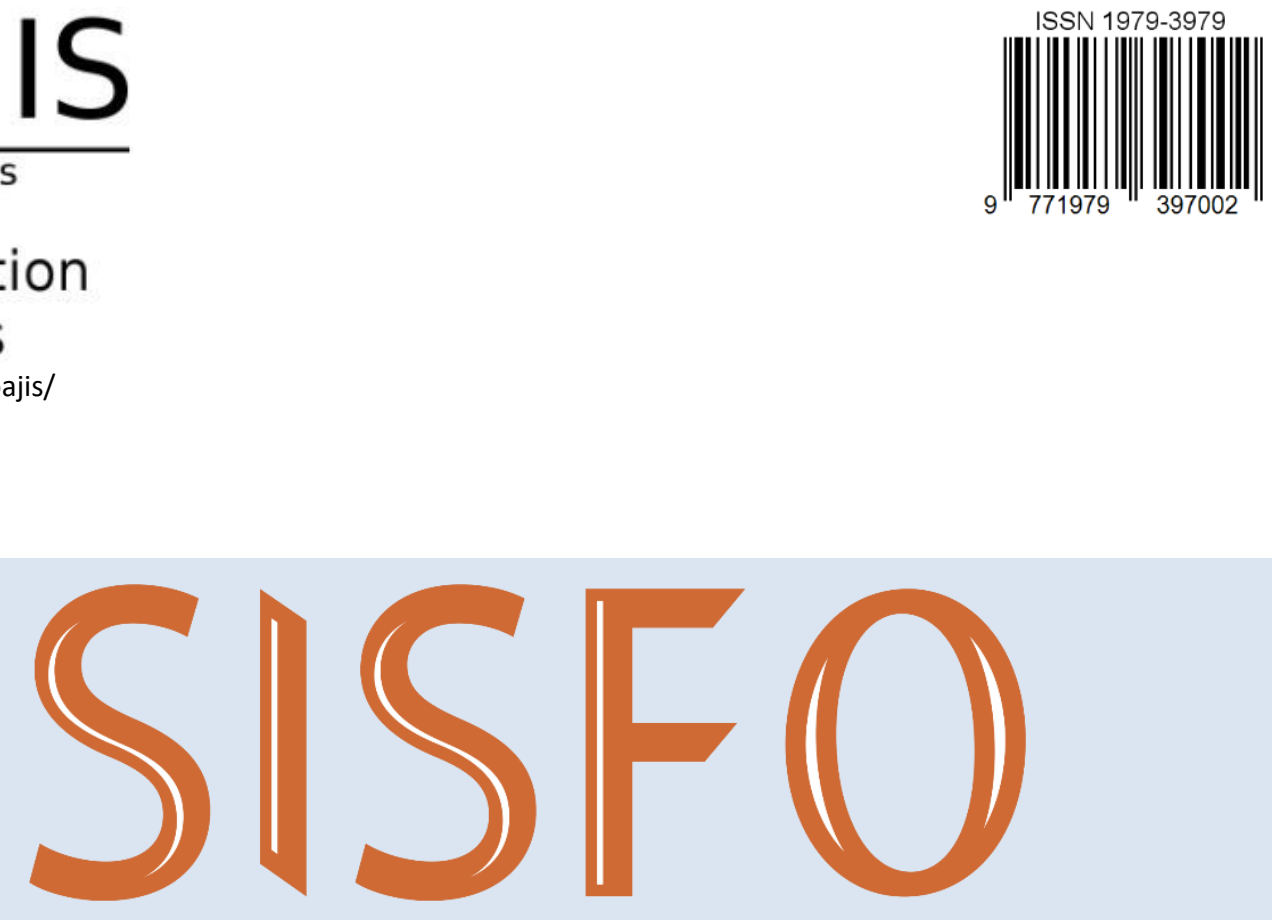

Inspirasi Profesional Sistem Informasi

\section{People}

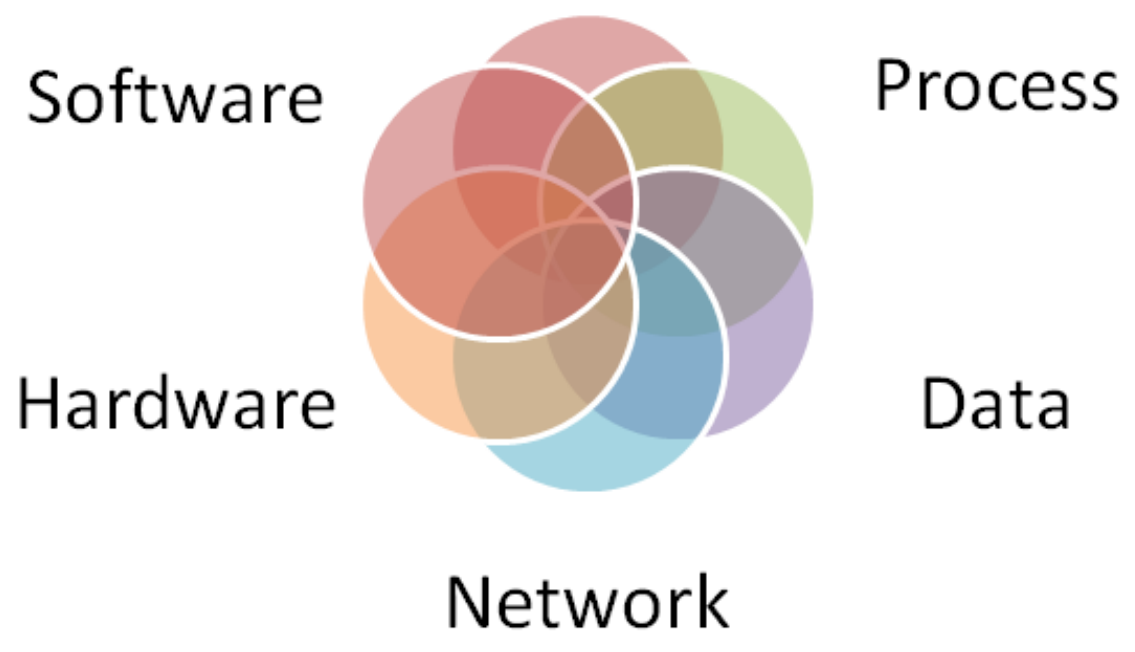


OAJIS

Journal of

Information

Systems

is.its.ac.id/pubs/oajis/

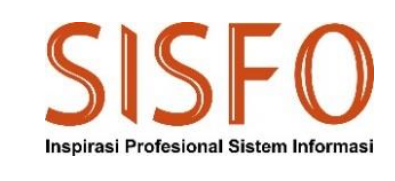

Jurnal Sisfo Vol. 08 No. 02 (2019) i-ii

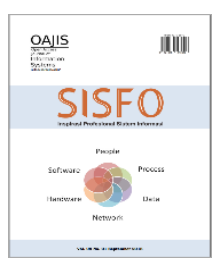

\section{Pimpinan Redaksi}

Faizal Mahananto

\section{Dewan Redaksi}

Eko Wahyu Tyas Darmaningrat

Amna Shifia Nisafani

Arif Wibisono

Rully Agus Hendrawan

\section{Tata Pelaksana Usaha}

\section{Achmad Syaiful Susanto}

Rini Ekowati

\section{Sekretariat}

Departemen Sistem Informasi - Fakultas Teknologi Informasi dan Komunikasi

Institut Teknologi Sepuluh Nopember (ITS) - Surabaya

Telp. 031-5999944 Fax. 031-5964965

Email: editor@jurnalsisfo.org

Website: http://jurnalsisfo.org

Jurnal SISFO juga dipublikasikan di Open Access Journal of Information Systems (OAJIS)

Website: http://is.its.ac.id/pubs/oajis/index.php 
OAJIS

Journal of

Information

Systems

is.its.ac.id/pubs/oajis/

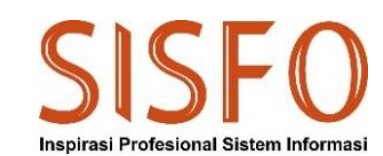

Jurnal Sisfo Vol. 08 No. 02 (2019) i-ii

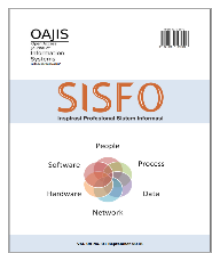

\section{Mitra Bestari}

Satria Fadil Persada, S.Kom., M.BA., Ph.D. (Institut Teknologi Sepuluh Nopember)

Sholiq, S.T., M.Kom., M.SA. (Institut Teknologi Sepuluh Nopember)

Nur Aini Rakhmawati, Ph.D. (Institut Teknologi Sepuluh Nopember)

Retno Aulia Vinarti, Ph.D. (Institut Teknologi Sepuluh Nopember)

Leon Andretti Abdillah, S.Kom., M.M. (Universitas Bina Darma)

Radityo Prasetianto W, S.Kom., M.Kom. (Institut Teknologi Sepuluh Nopember) 
OAJIS Journal of

Information

Systems

is.its.ac.id/pubs/oajis/

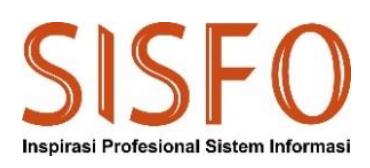

Jurnal Sisfo Vol. 08 No. 02 (2019) iii

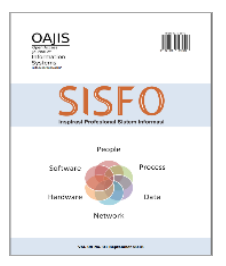

\section{Daftar Isi}

Evaluasi Kerangka Kerja Perencanaan Keberlangsungan Bisnis pada PT. Lotte Chemical Titan Nusantara

Mochammad Ikmal Amirullah, Apol Pribadi Subriadi......

ShopVis: Visualisasi Interaktif Persebaran Toko Daring di Indonesia Menggunakan Crowdsourced Data

Ruktin Handayani, Mohammad Arif Rasyidi. 99

Blended Learning dari Perspektif Para Guru Sekolah di Pondok Pesantren

Ahmad Muklason, Faizal Mahananto, Wiwik Anggraeni, Arif Djunaidy, Edwin Riksakomara .....

Pembuatan Prosedur dan Formulir Service Desk Pemerintahan Kota Madiun Berdasarkan ITIL V3

Zulaikah Effendi, Anisah Herdiyanti, Tony Dwi Susanto.

Rancang Bangun Dashboard dan Visualisasi Data Kickstarter dengan Pendekatan Business Intelligence

Irmasari Hafidz, Achmad Mirfak, Anisah Azhari, Aufar Ilham Adianto, Berry Humaidi Fuad, M. Ihsan Farabi .... 
Halaman ini sengaja dikosongkan 


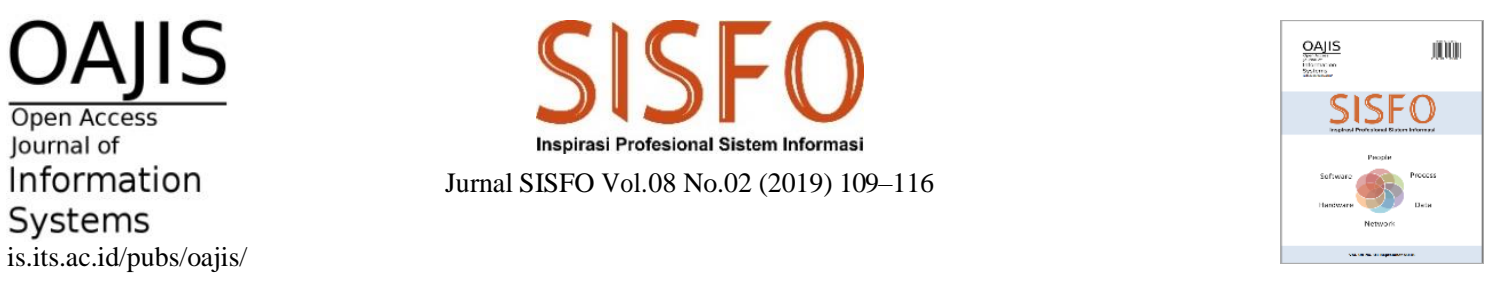

\title{
Blended Learning dari Perspektif Para Guru Sekolah di Pondok Pesantren
}

\author{
Ahmad Muklason*, Faizal Mahananto, Wiwik Anggraeni, Arif Djunaidy, Edwin Riksakomara \\ Departemen Sistem Informasi, Fakultas Teknologi Informasi dan Komunikasi, Institut Teknologi Sepuluh Nopember
}

\begin{abstract}
To survive the industrial revolution 4.0 which was marked by the massive use of digital technology, educational organizations are expected to do digital transformation. However, unfortunately it is commonly known that there is a gap in the use of technology in Indonesia between big cities and regions, between modern education system and traditional education system. To reduce this gap, blended learning technology training was held aimed for teachers in the Darul Ulum Islamic boarding school in Peterongan, Jombang. Pondok Pesantren Darul Ulum Islamic is a boarding school with almost 10,000 students. In the Darul Ulum Islamic boarding school its self there are various educational units ranging from primary school to higher education. This study focuses on investigating the online learning technology adoption by teachers in Islamic boarding school, especially their perspective on the technology. Our findngs showed that they are very ready to adopt the technology.
\end{abstract}

Keywords: Blended Learning, E-Learning, Islamic Borading School

\begin{abstract}
Abstrak
Untuk bisa bertahan pada revolusi industri 4.0 yang ditandai dengan masifnya penggunaan teknologi digital menuntut adanya transformasi digital pada organisasi pendidikan. Akan tetapi, sayangnya ada kesenjangan penggunaan teknologi di Indonesia antara di kota besar dan daerah, antara sistem pendidikan modern dan pendidikan tradisional seperti pondok pesantren. Untuk mengurangi kesenjangan tersebut, sebuah pelatihan teknologi blended learning telah diadakan yang ditujukan kepada para guru dan para ustadz atau ustadzah di pondok pesantren Darul Ulum di Peterongan Jombang. Pondok pesantren Darul Ulum adalah pondok pesantren dengan jumlah santri hampir 10.000. Di pondok pesantren Darul Ulum sendiri terdapat berbagai unit pendidikan mulai dari sekolah dasar hingga jenjang perguruan tinggi. Kajian ini bertujuan untuk menginvestigasi tingkat kesiapan adopsi teknologi blended learning para guru di pesantren. Secara ringkas dapat kami simpulkan bahwa, para guru di pondok pesantren darul ulum jombang sangat siap dalam mengadopsi teknologi blended learning.
\end{abstract}

Kata kunci: Blended Learning, E-Learning, Pondok Pesantren

(C) 2019 Jurnal SISFO.

Histori Artikel: Disubmit 07-01-2019; Direvisi 30-01-2019; Diterima 31-01-2019; Tersedia online 31-01-2019

*Corresponding Author

Email address: mukhlason@is.its.ac.id (Ahmad Muklason)

https://doi.org/10.24089/j.sisfo.2019.01.003 


\section{Pendahuluan}

Kota Jombang selama ini dikenal sebagai kota santri, karena di kota ini terdapat ribuan santri yang tersebar pada ratusan pondok pesantren. Di kota ini, terdapat empat pondok pesantren besar dengan jumlah santri di atas 5000 orang, yaitu: Pondok Pesantren Darul Ulum di Peterongan, Pondok Pesantren Bahrul Ulum di Tambak Beras, Pondok Pesantren Mambaul Maarif di Denanyar, dan Pondok Pesantren Tebu Ireng, di Cukir.

Pondok pesantren selama ini dikenal sebagai lembaga pendidikan tradisional yang mempertahankan tradisi pengajaran khas ala pesantren yang klasik seperti metode bandongan dan sorogan. Di sisi lain, perkembangan jaman yang semakin modern, lebih-lebih di era digital seperti ini, menuntut adanya transformasi pendidikan.

Menghadapi tantangan perubahan zaman dan modernitas ini, pondok pesantren memiliki sikap yang berbeda-beda. Ada pesantren yang kokoh mempertahankan tradisi klasik pesantrenya dan menolak modernitas, atau lebih dikenal dengan pondok pesantren syalafiyah. Tetapi ada juga pesantren yang mengambil jalan tengah, yaitu tetap mempertahankan metode klasik yang dirasa masih baik untuk dipertahankan, tetapi juga tidak menolak perubahan modernitas yang lebih baik. Model pesantren ini dikenal dengan pondok pesantren kholaf. Lihat [1] dan [2] untuk pembahasan lebih detail mengenai jenisjenis pesantren ini.

Pada pondok pesantren syalafiyah, biasanya memiliki sistem pendidikan berbasis pesantren yang tidak sama dengan kurikulum pemerintah. Kajian utama di pondok pesantren syalafiyah adalah mempelajari literatur islam klasik atau yang di pesantren lebih dikenal dengan istilah kitab kuning. Contoh pondok pesantren syalafiyah adalah pondok pesantren Lirboyo, Kediri dan pondok pesantren Sidogiri, Pasuruan. Sebaliknya pada pondok pesantren kholaf, selain memiliki kurikulum tambahan ciri khas pondok pesantren juga memiliki sistem pendidikan yang mengikuti kurikulum pemerintah. Salah satu pondok kholaf yang paling menonjol adalah pondok pesantren Darul Ulum, di Peterongan, Jombang. Pesantren ini memiliki unit pendidikan dari jenjang SD/MI hingga perguruan tinggi yang mana kurikulumnya sama persis dengan kurikulum pemerintah dengan tambahan muatan lokal kurikulum khas pesantren.

Pada penelitian ini, penulis berfokus pada kajian penerapan blended learning pada pondok pesantren kholaf. Representasi pondok pesantren kholaf yang dijadikan obyek penelitian ini adalah pondok pesantren Darul Ulum. Lebih khusus lagi, penelitian ini bertujuan untuk mengetahui persepsi guru-guru di pondok pesantren kholaf terhadap teknologi blended learning. Penelitian ini pada prinsipnya merupakan penelitian penerimaan guru terhadap teknologi online learning sebagaimana telah dilakukan pada penelitian terdahulu, seperti pada [3] dan [4].

\section{Tinjauan Pustaka}

Fokus pada tinjauan pustaka ini adalah tentang revolusi industi 4.0, blended learning, education 4.0, dan penelitian-penelitian sebelumnya.

\subsection{Revolusi Industri 4.0}

Istilah Industri 4.0 pertama kali muncul di Jerman, sebagai sebuah struktur baru dimana manufaktur dan sistem logistic dalam wujud Cyber Physical Production System (CPPS) secara intensif menggunakan jaringan informasi dan komunikasi global yang tersedia untuk pertukaran informasi secara ekstensif [5]. Sementara itu, pada [6] dijelaskan perkembangan industri, mulai dari revolusi industry 1.0 hingga revolusi industry 4.0. dimana disebutkan bahwa pada era revolusi industry 4.0, baris batas antara fisik, digital, dan biologis semakin kabur. Revolusi Industri 4.0, berdasarkan [7], didorong oleh empat teknologi utama, 
yaitu: Internet of Things (IoT), Industrial Internet of Things (IIoT), cloud-based manufacturing dan smart manufacturing.

Pada [8], direkomendasikan bahwa peserta didik seharusnya disiapkan untuk memenuhi kebutuhan masyarakat 4.0 dan industri 4.0. Salah satunya adalah dengan membangun collaborative virtual learning environment. Sementara itu studi pada [9], merekomendasikan adanya manajemen pembelajaran untuk merespon perubahan peserta didik pada masyarakat digital. Sementara itu, pada [10] dinyatakan bahwa respon pendidikan terhadap kebutuhan revolusi industri 4.0 disebut dengan Education 4.0. dimana manusia dan teknologi dapat menciptakan kemungkinan baru.

\subsection{Education 4.0}

Menurut [11], ada sembilan kecenderungan yang akan menjadi penciri pada education 4.0, yaitu: pertama, pembelajaran dapat dilakukan kapan saja dan dimana saja. Kedua, pembelajaran akan menjadi personal untuk masing individu. Ketiga, peserta didik memiliki pilihan untuk menentukan bagaimana mereka belajar. Keempat, peserta didik akan lebih diarahkan ke pembelajaran berbasis proyek. Kelima, peserta didik akan diarahkan ke hal-hal yang lebih praktikal (hand-on experience). Keenam, peserta didik akan diarahkan pada interpretasi data, dimana peserta didik diberikan data dan diharapakan dapat analisa dengan pengetahuan dan penalaran yang dimiliki. Ketujuh, pada setiap peserta didik akan dilakukan penilaian yang berbeda. Kedelapan, pendapat peserta didik akan dipertimbangkan dalam merancang dan memperbarui kurikulum. Kesembilan, peserta didik akan menjadi lebih mandiri dalam proses belajarnya.

Untuk memasuki era Education 4.0, guru diharapkan menguasai tools digital yang diperlukan untuk mengajar peserta didik dari generasi Z. Setidaknya ada 9 tools yang disarankan oleh [12] untuk dikuasai oleh para guru yang dirangkum pada Tabel 1. Penguasaan sembilan tools ini dipercaya sebagai keterampilan paling penting yang harus dikuasai oleh guru dalam pengajaran abad 21 .

\subsection{Blended Learning}

Meskipun tidak ada satu definisi yang bisa disepakati oleh setiap orang, secara garis besar, sebagaimana didiskusikan pada [13], ada tiga definisi blended learning yang biasa digunakan, yaitu: menggabungkan berbagai moda intruktusional (atau media instruksional) [14]; menggabungkan beberapa metode instruksional [15]; dan yang terakhir adalah antara online dan face-to-face [16]. Dalam konteks makalah ini, maka definisi yang paling tepat digunakan adalah definisi yang terakhir. Pada [13], dijelaskan bahwa setidaknya ada 4 dimensi dari interaksi baik pada face-to-face maupun sistem online sebagaimana diilustrasikan pada Gambar 1, yaitu: ruang, waktu, kesetiaan, dan kemanusiaan.

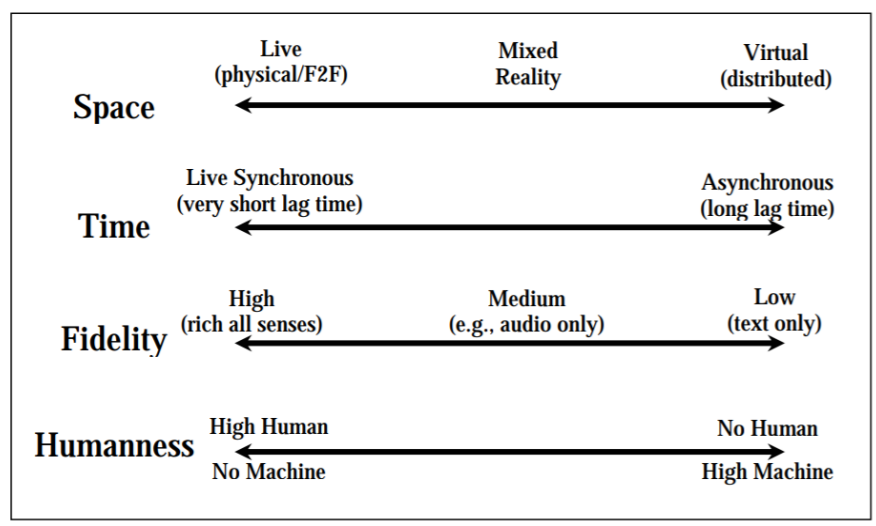

Gambar 1. Empat dimensi interaksi [13] 


\subsection{Penelitian Sebelumnya}

Sebagaimana dianalisis di [17], penelitian pada bidang blended learning sebagian besar berfokus pada perbandingan antara blended learning dengan face-to-face atau online learning. Aspek yang diteliti pada penelitian sebelumnya antara lain menginvestigasi: mana yang lebih penting untuk pembelajaran yang efektif apakah metode instruksional atau medianya. Selain itu, pada studi sebelumnya telah dikaji tentang perbandingan karakteristik peserta didik, lingkungan ruang kelas, retention rates, efektivitas dari kolaborasi, media pembelajaran yang disukai oleh peserta didik, kepuasan peserta didik, dan performa akademik.

Sementara itu, pada [18] dilakukan kajian tentang pengaruh blended learning terhadap motivasi belajar dan hasil belajar siswa tingkat SMK. Pada kajian tersebut disimpulkan bahwa blended learning mampu menaikan motivasi dan hasil belajar siswa SMK. Kajian yang serupa dengan obyek penelitian yang berbeda juga telah dilakukan pada [19]. Sedangkan penelitian pada [20] lebih berfokus pada pengukuran efektivitas penerapan blended learning di SMK Teknologi Informasi (TI) yang menyimpulkan bahwa secara umum pada banyak aspek blended learning terbukti sangat efektif.

Walaupun telah banyak kajian blended learning sebelumnya, akan tetapi belum ada kajian khusus mengenai blended learning di pondok pesantren. Sepanjang pengetahuan penulis, ini adalah kajian pertama yang mengulas blended learning di pondok pesantren. Pondok pesantren adalah sistem pendidikan khas Indonesia yang jumlahnya ribuan, yang sebagian besar berada di pedesaan, sehingga kajian penting dan menarik untuk dilakukan. Disisi lain, sebagaimana telah diteliti pada [21], terdapat kesenjangan digital di Indonesia antara di desa dan di kota. Penelitian dapat digunakan untuk mengkaji apakah adanya kesenjangan digital ini berpengaruh pada tingkat penerimaan guru terhadap teknologi online/blended learning.

Tabel 1. Keterampilan digital yang diperlukan oleh guru

\begin{tabular}{|c|c|}
\hline Keterampilan Digital & Tools \\
\hline Merekam dan mengedit klip audio & Soundcloud, audioboo, Vocaroo, clyp \\
\hline Membuat materi audio yang interaktif dan menarik & $\begin{array}{l}\text { Blubbr, Magisto, Teachem, TED Ed, Edpuzzle, Wevideo, } \\
\text { Videonotes, YouTube video editor }\end{array}$ \\
\hline Membuat materi visual yang menarik & Piktochart, Canva, Glogster, Thinglink, Google draw \\
\hline Menggunakan media jejaring sosial & Twitter, Facebook, Google Plus, LinkedIn \\
\hline $\begin{array}{l}\text { Menggunakan blog dan wiki untuk memberikan ruang bagi } \\
\text { peserta didik untuk berpartisipasai dalam proses pembelajaran }\end{array}$ & Blogger, WordPress, Kidblog, Wikispaces, Edublog, Weebly \\
\hline $\begin{array}{l}\text { Menggunakan website social bookmarking untuk dibagikan di } \\
\text { kelas }\end{array}$ & Diigo, Scoop.it, Edshelf, Educlipper, Pinterest, Symbaloo \\
\hline Membuat presentasi yang menarik & Prezi*, Haiku, Deck, Google Slides, Zoho Presentation \\
\hline Membuat Portfolio digital & SeeSaw, Pathbrite, Silk, Weebly, Google sites \\
\hline Membuat Quiz yang interaktif & Testmoz, Quizalize, Riddle, QuizBean, Flipquiz \\
\hline
\end{tabular}

*) digunakan dalam pelatihan 


\section{Metodologi}

Secara ringkas, metodologi penelitian ini dapat dijelaskan sebagai berikut:

\subsection{Pelatihan}

Karena keterbasan waktu pelatihan, pada pelatihan ini hanya dipilih beberapa tools saja dari tools yang direkomendasikan pada Tabel 1. Tools yang dipilih adalah tools yang diperkirakan paling mudah dikuasai oleh para guru di pesantren. Pelatihan dilaksanakan secara blended learning: yaitu satu hari face-to-face, dan satu minggu belajar secara daring. Materi yang diberikan meliputi teori tentang revolusi industri 4.0, education 4.0, dan blended learning. Selanjutnya adalah pelatihan hands-on yang lebih praktikal meliputi: zip grade, cam scanner, kahoot, powtoon, prenzi, dan google classroom. Dalam kegiatan penelitian ini telah diikuti peserta guru dari berbagai unit pendidikan di pondok pesantren Darul Ulum sebanyak 43 peserta.

\subsection{Kuesioner}

Setelah pelatihan, kepada peserta pelatihan diberikan kuesioner. Tujuan dari kuesioner ini adalah untuk mengetahui bagaimana komentar peserta terhadap pelatihan ini dan untuk menggali perspektif para peserta terhadap teknologi blended learning. Sebagian besar pertanyaan adalah pertanyaan tertutup agar fokus dari penelitian ini tidak melebar. Selanjutnya, agar dapat dianalisa keterkaitan antara perspektif peserta terhadap blended learning dengan demografi peserta, dalam kuesioner ini ditanyakan pertanyakan demografis mengenai umur, jenis kelamin, dan jenjang pendidikan dimana peserta pelatihan mengajar. Kuesioner terdiri dari 8 pertanyaan yang terbagi menjadi dua bagian. Bagian pertama berisi pertanyaan perspektif para peserta terhadap pelatihan blended learning ini. Sementara itu, bagian kedua berisi pertanyaan demografi peserta. Sebagian besar pertanyaan adalah pertanyaan tertutup.

\subsection{Analisa}

Pada tahap ini data yang diperoleh dari kuesioner dianalisa. Analisa pada tahap ini adalah analisa kuantitatif dan kualitatif. Pada analisa kuantitatif akan dianalisa berapa persen yang memiliki perspektif positif dibanding perspektif negatif baik terhadap pelatihan maupun terhadap teknologi blended learning. Sedangkan analisa kualitatif ditujukan untuk menggali lebih detail komentar, kesan, dan perspektif peserta pelatihan terhadap teknologi blended learning, khususnya apa yang mereka sukai dan apa yang kurang mereka sukai.

\section{Hasil dan Pembahasan}

Dari 43 peserta pelatihan diperoleh umpan balik sebanyak 40 (response rate: 93\%). Demografi peserta dapat dijelaskan sebagai berikut: Dari jenis kelamin, tiga perempat peserta pelatihan $(75 \%)$ adalah guru perempuan. Sebagian besar peserta pelatihan berumur 21-50 tahun (Lihat Gambar 2). Menariknya ada 7\% dari peserta yang telah berumur lebih dari 50 tahun. Dari keseluruhan peserta, $3 / 4$ nya adalah guru di tingkat SMA/SMK/MA, sedangkan sisanya adalah guru SMP.

Secara garis besar, peserta pelatihan memberi respon yang sangat positif terhadap pelaksanaan pelatihan ini. Dari segi pelaksanaan, $41 \%$ dari peserta berpendapat bahwa pelatihan yang dilaksanakan sangat sesuai dengan yang mereka harapkan, sementara 56\% nya berpendapat sesuai dengan yang mereka harapkan. Bagi sebagian besar peserta pelatihan (60\%) materi yang disampaikan tergolong mudah untuk diikuti sangat bahkan sangat mudah (17.5\%). Akan tetapi masih ada $15 \%$ dari peserta yang merasa kesulitan mengikuti pelatihan ini. $76 \%$ dari peserta berfikir pelatihan ini sangat membantu mereka dalam menciptakan suasana kelas yang efektif, dan sisanya sekitar $34 \%$ berfikir cukup membantu. Disisi lain, 
97\% dari peserta berencana untuk menerapkan materi yang diperoleh pada kelas mereka. Dari sini dapat disimpulkan bahwa tingkat penerimaan para guru di pondok pesantren Darul Ulum terhadap teknologi blended learning sangat tinggi, yaitu $97 \%$.

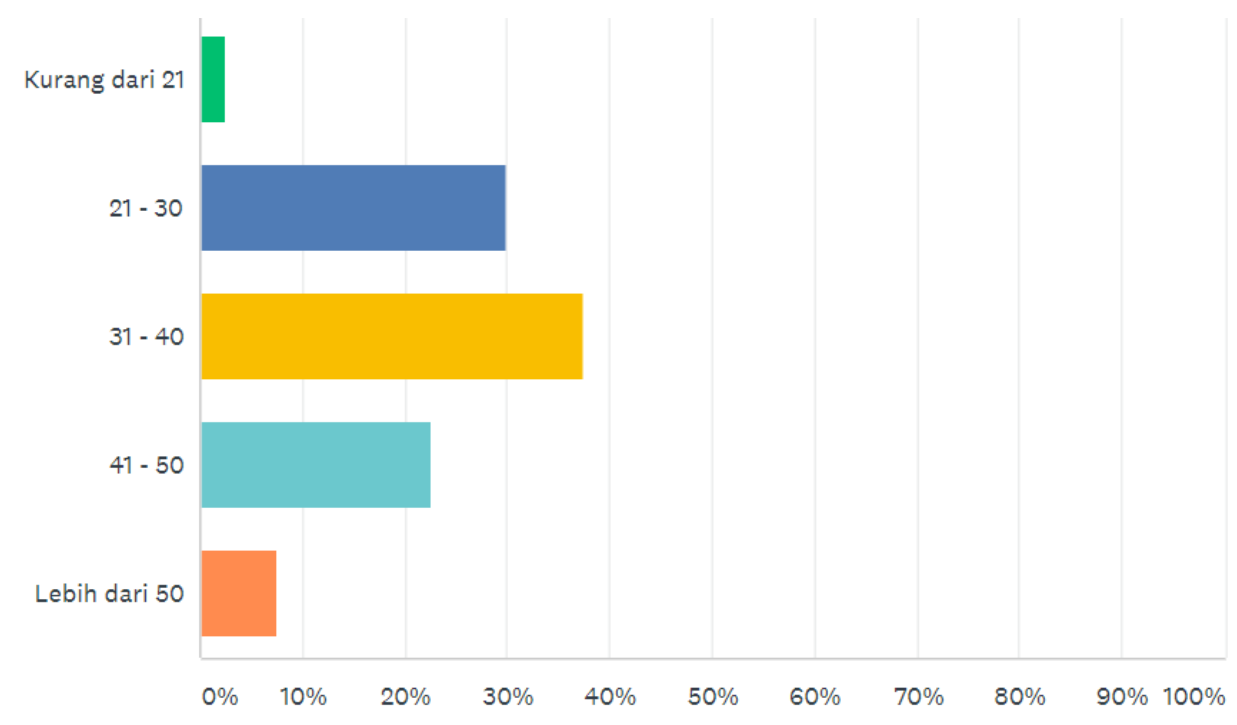

Gambar 2. Persebaran umur peserta pelatihan

Persepsi peserta terhadap pelatihan blended learning ini diantaranya adalah menyenangkan, sangat membantu dalam menerapkan metode yang menarik, sangat menarik, menambah wawasan baru, sangat bermanfaat, luar biasa dan berkesan, membuat penasaran, sangat bagus, dan bagus. Sebagian besar arapan peserta pelatihan terhadap pelatihan ini adalah agar pelatihan ini diadakan kembali dengan durasi pelatihan yang lebih lama, peserta lebih banyak, dan materi yang lebih banyak lagi.

\section{Kesimpulan}

Secara ringkas hal-hal yang dapat disimpulkan dari penelitian ini adalah sebagai berikut:

\subsection{Simpulan}

Pelatihan ini sangat diterima positif oleh guru-guru di pondok pesantren. Ini adalah pelatihan baru yang belum pernah mereka dapatkan sebelumnya. Semua peserta setuju bahwa pelatihan ini sangat membantu atau cukup membantu dalam menciptakan suasana kelas yang lebih efektif. Dari sisi tingkat penerimaan para guru terhadap teknologi blended learning, juga ditemukan sangat tinggi, hal ini dibuktikan dari hasil kuesioner yang menunjukkan bahwa 97\% dari peserta berencana untuk menerapkan teknologi blended learning pada kelas yang mereka ajar.

\subsection{Saran}

Sampel pondok pesantren yang dipilih dalam pelatihan ini adalah pondok pesantren yang masuk dalam kategori kholaf atau modern. Kedepanya pelatihan serupa dapat diadakan pada pondok pesantren dengan sistem yang masih tradisional atau pondok pesantren syalaf bukan di pondok pesantren yang sudah modern seperti pondok pesantren Darul Ulum Jombang. Sehingga dapat diketahui perbedaan persepsi guru di pondok pesantren yang modern dan pondok pesantren tradisional dan kajian mengenai perspektif dan 
tingkat penerimaan para guru di pesantren dapat dikaji lebih komprehensif. Selain itu, dalam penelitian ini obyek penelitian hanya para guru, pada penelitian berikutnya kajian yang sama dapat dilakukan kepada para murid atau santri di pondok pesantren.

\section{Daftar Rujukan}

[1] W. Bachtiar, Perkembangan Pesantren di Jawa Barat. Bandung: Balai Penelitian IAIN Sunan Gunung Djati, 1990.

[2] J. Muhammad, Metamorfosis Pesantren Di Era Globalisasi. KARSA: Journal of Social and Islamic Culture, 20(1), pp. 127-139, 2012.

[3] S. BošTjan, M. HeričKo, M. PušNik, A meta-analysis of e-learning technology acceptance: The role of user types and e-learning technology types. Computers in Human Behavior, 27 (6), pp. 2067-2077, 2011.

[4] C. Hong-Ren, H. Tseng, Factors that influence acceptance of web-based e-learning systems for the in-service education of junior high school teachers in Taiwan. Evaluation and program planning, 35 (3), pp. 398-406, 2012.

[5] M.A.K. Bahrin, M.F. Othman, N.H. Nor, M.F.T. Azli, Industry 4.0: A Review on Industrial Automation and Robotic. Jurnal Teknologi (Sciences \& Engineering), pp. 137-143, 2016.

[6] K. Shwab, The Fourth Industrial Revolution: what it means, how to respond, 2016. Available at: https://www. weforum.org/agenda/2016/01/the-fourth-industrial-revolution-what-it-means-and-how-to-respond. [Accessed: 6 February 2019]

[7] S. Erol, A. Jäger, P. Hold, K. Ott, W. Sihn, Tangible Industry 4.0: a scenario-based approach to learning for the future of production, 6th CIRP Conference on Learning Factories, Procedia CIRP, pp. 13 - 18, 2016.

[8] S. Katharina, et al., Preparing for industry 4.0-collaborative virtual learning environments in engineering education.St. Theresa Journal of Humanities and Social Sciences, 2(2), pp. 477-487, 2016.

[9] V. Puncreobutr, Education 4.0: New Challenge of Learning, St. Theresa Journal of Humanities and Social Sciences, $2(2), 2016$.

[10] H. Anealka, Education 4.0 Made Simple: Ideas for Teaching. International Journal of Education and Literacy Studies, 6(3), pp. 92-98, 2018.

[11]P. Fisk, Education 4.0: the future of learning will be dramatically different, in school and throughout life, 2017. Available at: http://www.thegeniusworks.com/2017/01/future-education-young-everyone-taught-together., [Accessed: 6 February 2019]

[12]Education technology and Mobile Learning, 2016. 9 fundamental digital skills for 21st century teachers. Available at: https://www.educatorstechnology. com/2016/12/9-fundamental-digital-skills-for-21st. html, [Accessed: 6 February 2019]

[13] G.R. Charles, Blended learning systems. The handbook of blended learning, pp. 3-21, 2016.

[14] Bersin \& Associates, Blended learning: What works? An industry study of the strategy, implementation, and impact of blended learning, Bersin \& Associates, 2003.

[15] M. Driscoll, Blended Learning: Let's get beyond the hype. elearning, pp. 54, 2002.

[16] J. Reay, Blended learning - a fusion for the future. Knowledge Management Review, 4(3), pp. 6, 2001.

[17] S.D. Jeffery, An analysis of research trends in dissertations and theses studying blended learning. The Internet and Higher Education 17, pp. 90-100, 2013.

[18] S.B. Sjukur, Pengaruh blended learning terhadap motivasi belajar dan hasil belajar siswa di tingkat SMK. Jurnal Pendidikan Vokasi, 2(3), 2012.

[19]F. Emria, I. Ifdil, I. Neviyarni, Efektivitas layanan informasi dengan menggunakan metode blended learning untuk meningkatkan motivasi belajar. Jurnal Psikologi Pendidikan dan Konseling: Jurnal Kajian Psikologi Pendidikan dan Bimbingan Konseling 2(2), pp. 84-92, 2016.

[20]D.D.G. Hendra, Evaluasi pelaksanaan blended learning di SMK TI Udayana menggunakan model CSE-UCLA. Jurnal Pendidikan Vokasi, 7(1), pp. 64-77, 2017.

[21]P. Lia, K. Ishii, Digital divides and mobile Internet in Indonesia: Impact of smartphones. Telematics and Informatics, 33(2), pp. 472-483, 2016. 
Ahmad Muklason et al. / Jurnal SISFO Vol.08 No.02 (2019) 109-116

Halaman ini sengaja dikosongkan 
